\title{
Drainage van symptomatische lymfoceles na pelviene lymfeklierdissectie: een retrospectief overzicht met langdurige follow-up
}

\author{
Elke Bovelander ${ }^{1}$ Oscar R. Brouwer' $\cdot$ Erik J. van Gennep ${ }^{1} \cdot$ Rob F. M. Bevers ${ }^{1} \cdot$ Tim Buddingh $^{2}$
}

Published online: 13 June 2018

(c) The Author(s) 2018

\section{Samenvatting}

Een klein deel van de lymfoceles na een pelviene lymfeklierdissectie (PLKD) wordt symptomatisch en behoeft drainage. De incidentie wordt wellicht onderschat, aangezien geïnfecteerde lymfoceles ook nog lang na de ingreep kunnen optreden en daardoor ontbreken in de standaard complicatieregistraties. Deze studie geeft een overzicht van de presentatie, kweekresultaten en behandeling van symptomatische (veelal geïnfecteerde) lymfocele. Hiertoe is een retrospectieve analyse verricht van de data van alle patiënten die tussen 2005 en 2016 een laparoscopische extraperitoneale standaard-PLKD voor prostaatkanker ondergingen $(n=280) .10 \%$ bleek percutane drainage van een symptomatische lymfocele nodig te hebben gehad, met een mediane drainageduur van negen dagen; $32 \%$ van de patiënten had meerdere drainages nodig. Opvallend was dat de helft van de patiënten zich langer dan één maand na de PLKD presenteerden, en een enkele patiënt zelfs pas na 17 maanden.

Trefwoorden lymfocele $\cdot$ pelviene lymfeklierdissectie $\cdot$ prostaatkanker $\cdot$ drainage $\cdot$ radicale prostatectomie

\section{Drainage of symptomatic lymphoceles after laparoscopic pelvic lymph node dissection: a retrospective evaluation with long-term follow-up}

\begin{abstract}
A small proportion of lymphoceles after pelvic lymph node dissection (PLND) becomes symptomatic and requires drainage. The incidence may have been previously underestimated as infected lymphoceles have been reported to occur long after PLND. They may therefore be missed by most complication registries. The aim of this study is to describe presentation, microbiology results, treatment and outcome of symptomatic (often infected) lymphoceles after PLND for prostate cancer with a long-term follow-up. This study was a retrospective analysis of all patients who underwent extraperitoneal standard PLND for prostate cancer between 2005 and 2016. A total number of 280 patients underwent a PLND and 28 of them required percutaneous drainage of a symptomatic lymphocele. Median drainage duration was 9 days and $32 \%$ of patients required multiple drainage procedures. The most striking finding was that half of these patients present more than one month after the initial surgery, with intervals up to 17 months.
\end{abstract}

Keywords lymphocele $\cdot$ pelvic lymph node dissection $\cdot$ prostate cancer $\cdot$ drainage $\cdot$ radical prostatectomy

\section{Inleiding}

drs. Elke Bovelander

elke.bovelander@ziggo.nl

1 afdeling Urologie, Leids Universitair Medisch Centrum, Leiden, Nederland

2 afdeling Urologie, Hagaziekenhuis, Den Haag, Nederland
Het verrichten van een pelviene lymfeklierdissectie (PLKD) levert belangrijke informatie op voor de stadiëring van de patiënten met prostaatkanker. Alhoewel een therapeutisch voordeel nog niet aangetoond is, laten enkele retrospectieve studies zien dat een uitgebreide lymfeklierdissectie bij patiënten met positieve klieren mogelijk therapeutisch 
zou kunnen werken [1-4]. Bij de traditionele lymfeklierdissectie worden in elk geval de lymfeklieren langs de vena iliaca externa en in de fossa obturatorius verwijderd [2].

De vorming van een lymfocele na een PLKD is een bekende complicatie, met een incidentie van ongeveer 27-61\% ingeval beeldvorming routinematig wordt verricht binnen één maand na de ingreep [1]. Voor het ontstaan van een lymfocele worden de volgende potentiële risicofactoren beschreven: de mate van dissectie, wel of geen intraperitoneale communicatie en het gebruik van profylactische heparine [5, 6]. De meeste lymfoceles zijn asymptomatisch en worden in de loop van de tijd geresorbeerd, waardoor ze geen verdere behandeling behoeven. Bij een klein deel van de patiënten treden echter wel klachten op, zoals pijn in de buik of tekenen van infectie, waardoor drainage geïndiceerd is. Van symptomatische lymfoceles wordt een incidentie beschreven die varieert tussen de 0 en $8 \%$ [2]. De reden dat sommige lymfoceles wel worden geresorbeerd en andere niet, blijft in de huidige literatuur onduidelijk.

In verschillende studies is beschreven dat lymfoceles ook nog maanden na de ingreep symptomatisch kunnen worden $[3,7]$. Veel complicatieregistraties bevatten gegevens van de eerste 30 dagen na de ingreep, wat tot onderschatting van de werkelijke incidentie van symptomatische lymfoceles kan leiden. Het doel van deze studie is een gedetailleerd overzicht te geven - met langdurige follow-up - van de patiënten bij wie na een lymfeklierdissectie vanwege prostaatcarcinoom percutane drainage noodzakelijk was in verband met een symptomatische lymfocele.

\section{Materiaal en methode}

Deze studie betreft een retrospectieve analyse van alle patienten die tussen 2005 en 2016 een PLKD vanwege prostaatkanker ondergingen. Het MSKCC-nomogram is gebruikt om het risico op lymfekliermetastasen te schatten. Bij patiënten die een radicale prostatectomie ondergingen werd een PLKD verricht als het risico op lymfekliermetastasen $>10 \%$ was. Bij patiënten die met externe radiotherapie werden behandeld, werd een PLKD uitgevoerd ter stadiëring als het risico op lymfekliermetastasen $>10-15 \%$ was (afhankelijk van de comorbiditeit). In deze studie werden patiënten geïncludeerd die percutane drainage van een symptomatische lymfocele ondergingen. De verzamelde informatie betrof patiëntkarakteristieken (leeftijd, diabetes, immuunsuppressie), de operatie (simultane prostatectomie, plaatsing van een drain, fenestratie, het aantal verwijderde lymfeklieren), de presentatie (tekenen van infectie, aantal dagen tot presentatie) en drainage-informatie (kweken, duur, antibiotische behandeling). Er was een follow-up van ten minste 18 maanden.
In ons centrum zijn de lymfeklieren laparoscopische extraperitoneaal verwijderd, langs de vena iliaca externa en de fossa-obturatorius-klieren. Indien de urinedipstick positief was voor nitriet of leukocyten werd antibiotische profylaxe gegeven. Afhankelijk van het intraoperatieve beloop (naar keuze van de operateur) werd een peritoneale fenestratie verricht en/of een drain geplaatst.

Postoperatieve beeldvorming in de vorm van een echo abdomen of CT-scan vond alleen plaats op indicatie, bijvoorbeeld bij pijn in de buik of bij tekenen van infectie. Indien nodig, werd drainage van een lymfocele in een steriele omgeving verricht door een interventieradioloog. Het gedraineerde lymfevocht werd ter analyse opgestuurd naar het microbiologisch laboratorium. Bloedkweken werden alleen afgenomen bij koorts. Antibiotische behandeling werd gestart bij tekenen van infectie en/of verhoogde ontstekingswaarden in het serum.

De statistische analyse werd uitgevoerd met SPSS versie 24. Normaal verdeelde variabelen werden gepresenteerd als gemiddelde met standaarddeviaties. Niet-normaal verdeelde variabelen werden weergegeven als mediaan met spreiding of als interkwartielafstand. Met een omgekeerde

Tabel 1 Patiënt- en operatiekarakteristieken

\begin{tabular}{|c|c|}
\hline variabelen, $n=28$ & waarden \\
\hline$\overline{\text { leeftijd (jaar) }}$ & $67 \pm 5$ \\
\hline diabetes & $4(14,3 \%)$ \\
\hline \multicolumn{2}{|l|}{ klinisch T-stadium } \\
\hline$-\mathrm{T} 1$ & $2(7,1 \%)$ \\
\hline$-\mathrm{T} 2$ & $9(32,1 \%)$ \\
\hline$-\mathrm{T} 3$ & $16(57,1 \%)$ \\
\hline$-\mathrm{T} 4$ & $1(3,6 \%)$ \\
\hline \multicolumn{2}{|l|}{ Gleason-score } \\
\hline-7 & $13(46,4 \%)$ \\
\hline-8 & $7(25 \%)$ \\
\hline-9 & $7(25 \%)$ \\
\hline-10 & $1(3,6 \%)$ \\
\hline iPSA & mediaan $20(\mathrm{IQR}=10-30)$ \\
\hline Kattan-score & mediaan $37(\mathrm{IQR}=17-60)$ \\
\hline aantal lymfeklieren & mediaan $6(\mathrm{IQR}=4-10)$ \\
\hline aantal patiënten met $N+$ & $5(18 \%)$ \\
\hline aantal metastasen (van $N+$ patiënten) & mediaan 2 (spreiding 1-15) \\
\hline prostatectomie & $2(7,1 \%)$ \\
\hline fenestratie & $3(10,7 \%)$ \\
\hline operatieve drainage & $8(28,6 \%)$ \\
\hline \multicolumn{2}{|l|}{ behandeling } \\
\hline$-\mathrm{EBRT}+\mathrm{HTx}$ & $23(82,1 \%)$ \\
\hline$-\mathrm{HTx}$ & $3(10,7 \%)$ \\
\hline - salvage ERBT & $1(3,6 \%)$ \\
\hline - follow-up & $1(3,6 \%)$ \\
\hline tijd tot presentatie (dagen) & $\begin{array}{l}\text { mediaan } 30 \\
\text { (spreiding } 8-518 \text { ) }\end{array}$ \\
\hline
\end{tabular}

EBRT external beam radiation therapy, HTx hormoontherapie 


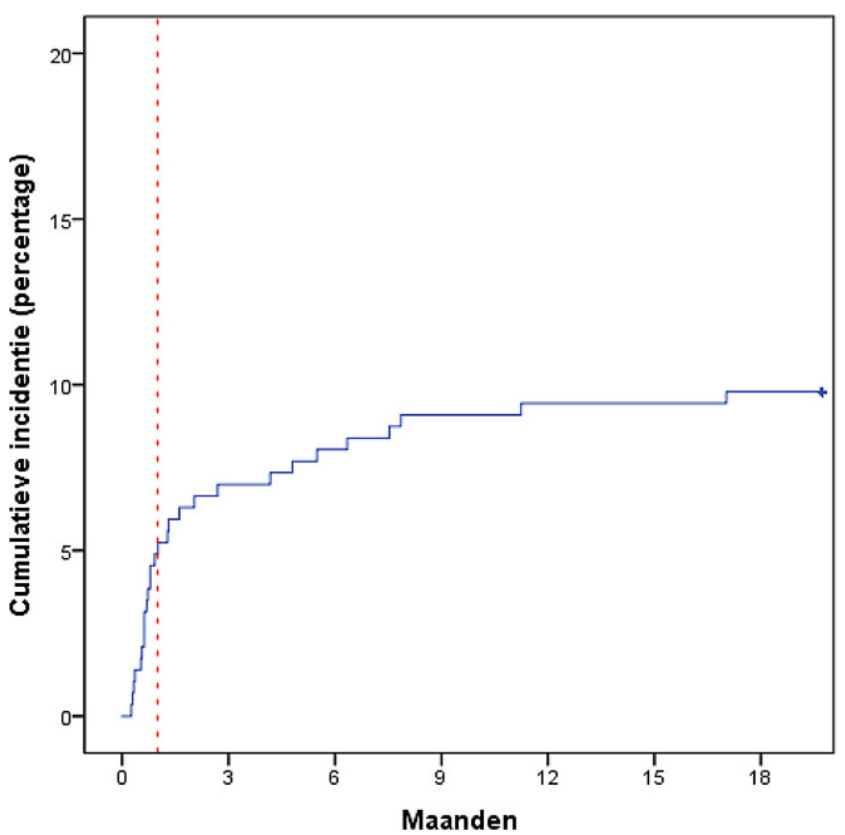

Figuur 1 Interval tussen PLKD en het optreden van symptomatische lymfocele

Kaplan-Meiercurve is het interval tussen de ingreep en de presentatie van de lymfoceles weergegeven.

\section{Resultaten}

\section{Patiënt- en operatiekarakteristieken}

In totaal ondergingen 280 patiënten een PLKD. Bij 28 patiënten $(10,0 \%)$ werd een percutane drainage van een symptomatische lymfocele verricht. Zie tab. 1 voor de overige karakteristieken. Geen van de patiënten gebruikte immunosuppressiva. Bij drie patiënten $(10,7 \%)$ werd een peritoneale fenestratie verricht, bij acht $(28,6 \%)$ werd een peroperatieve drain geplaatst, welke één dag na de ingreep werd verwijderd en $82,1 \%$ van de patiënten werd behandeld met externe radiotherapie gecombineerd met androgeensuppressietherapie gedurende twee tot drie jaar.

\section{Presentatie van de lymfocele}

Het mediane interval tussen de PLKD en presentatie van lymfocele bedroeg 30 dagen, met een spreiding van 8-518 dagen (fig. 1). De meeste patiënten presenteerden zich met koorts $(59,3 \%)$ of pijn in de buik $(64 \%)$. Het gemiddelde C-reactieve proteïne (CRP) was verhoogd en bij veel patiënten was sprake van leukocytose (tab. 2).
Tabel 2 Symptomen en aanvullend onderzoek bij presentatie

\begin{tabular}{lcl}
\hline variabelen, $n=28$ & waarden & $\begin{array}{l}\text { geen } \\
\text { data }\end{array}$ \\
\hline koorts & $16(59,3 \%)$ & 1 \\
buikpijn & $16(64 \%)$ & 3 \\
leukocyten & $13,1 \pm 5,9$ & 8 \\
CRP & $164,6 \pm 117,5$ & 9 \\
positieve kweek van lymfe- & $19(70,4 \%)$ & 1 \\
vocht & & \\
bloedkweek & & 0 \\
- positief & $2(7,1 \%)$ & \\
- negatief & $14(50 \%)$ & \\
- niet verricht & $12(42,9 \%)$ & \\
CRP C-reactieve proteïne & & \\
Microbiologie & &
\end{tabular}

Van 25 patiënten waren kweken van het lymfevocht beschikbaar, die bij 19 patiënten positief waren. Bij die 19 patiënten werden in totaal 26 bacteriën geïdentificeerd, aangezien bij drie patiënten meerdere bacteriën uit de kweek kwamen. Het betrof met name Gram-positieve bacteriën die de huid als normale habitat hebben. Het vaakst werden betahaemolytische streptokokken (8/26) en coagulase negatieve stafylokokken (5/26) gevonden. Slechts twee patiënten $(7,1 \%)$ hadden positieve bloedkweken. In tab. 3 staan alle bacteriën die uit het gedraineerde lymfevocht gekweekt werden.

\section{Behandeling}

Alle patiënten werden behandeld met percutane drainage van de symptomatische lymfocele. Het mediaan aantal drainage dagen was negen (IQR $=2-14)$. Het grootste deel van de patiënten werd gelijktijdig behandeld met antibiotica $(78,3 \%)$ (tab. 4). Bij negen patiënten waren meerdere drainages nodig vanwege aanhoudende klachten bij een persisterende lymfocele.

\section{Discussie}

De incidentie van lymfoceles loopt in de huidige literatuur sterk uiteen en is in grote mate afhankelijk van het al dan niet verrichten van routinematige beeldvorming na de ingreep. In de studie van Orvieto et al. werd bij alle patiënten een CT-scan verricht en zodoende werd een incidentie van $51 \%$ gevonden [8]. In een recente systematische review beschrijven Ploussard et al. echter een incidentie van $0-8 \%$ [2]. In onze studie werd een incidentie van $10 \%$ gezien, wat grotendeels kan worden verklaard uit de langdurige follow-up. In de meeste studies wordt echter weinig 
Hier staat een advertentie.

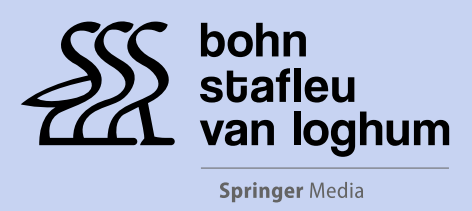

Houten 2018 
Hier staat een advertentie.

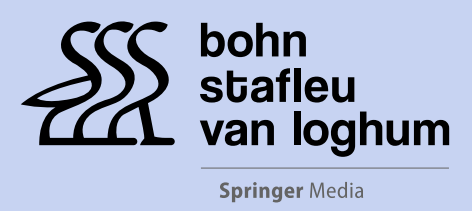

Houten 2018 
Tabel 3 Uitslagen van lymfevochtkweken

\begin{tabular}{lc}
\hline uitslag kweek & incidentie \\
\hline niet verricht & 3 \\
negatief & 6 \\
Gram-positieve bacteriën & 21 \\
- Beta-haemolytische streptococcus groep A & 1 \\
- Beta-haemolytische streptococcus groep B & 5 \\
(S. Agalactiae) & \\
- Beta-haemolyticsche streptococcus groep G & 2 \\
- Streptococcus milleri & 1 \\
- Streptococcus species & 1 \\
- Enterococcus faecalis & 1 \\
- Peptostreptococcus magnus & 1 \\
- Peptostreptococcus anaerobius & 1 \\
- Staphylococcus aureus & 1 \\
- Staphylococcus lugdunensis (CNS) & 3 \\
- Staphylococcus epidermidis CNS) & 1 \\
- Staphylococcus hominis (CNS) & 1 \\
- Aerococcus urinae & 1 \\
- Anaerobe cocci & 1 \\
Gram-negatieve bacteriën & 5 \\
- Stenotrophomonas maltophilia & 1 \\
- Enterobacter aerogenes & - Prevotella species \\
- Escherichia coli (EC) & 1 \\
\hline CNS cog & 1 \\
\hline
\end{tabular}

CNS coagulasenegatieve stafylokok

nadruk gelegd op de tijd tussen de PLKD en het optreden van een symptomatische lymfocele.

De meest opvallende bevinding van deze studie is dat de helft van de patiënten zich pas een maand na de ingreep presenteerde met intervallen die opliepen tot zelfs 17 maanden.

In een casusbeschrijving van Tremp et al. worden twee casussen besproken met een lang tijdsinterval tot presentatie van geïnfecteerde lymfocele, namelijk 8 en 20 maanden [7]. Ook in enkele cohortstudies worden intervallen beschreven van drie tot 19 weken [3, 8-10]. In de retrospectieve studie van Hamada et al. wordt een gemiddelde tijd tot diagnose van $19 \pm 52$ weken beschreven in de groep met steriele kweken. Alhoewel de auteurs hier niet specifiek de aandacht op richten, presenteerden enkele patiënten zich dus pas na 16 maanden [3]. Vaak wordt één maand als grens gebruikt voor postoperatieve complicatieregistratie, hetgeen kan leiden tot aanzienlijke onderschatting van symptomatische lymfoceles na PLKD.

PLKD wordt in het algemeen beschouwd als een relatief kleine ingreep, die vaak in een ziekenhuisopname van één nacht of zelfs in dagopname wordt uitgevoerd. Uit onze resultaten blijkt echter dat een symptomatische lymfocele gepaard gaat met significante ziektelast voor de patiënt, omdat een groot deel van de patiënten meer dan één week een
Tabel 4 Behandeling van lymfoceles

\begin{tabular}{lll}
\hline & waarden & n.b. \\
\hline duur van drainage (dagen) & $\begin{array}{l}\text { mediaan } 9 \\
\text { (IQR 2-14) }\end{array}$ & 9 \\
$\begin{array}{l}\text { aantal patiënten voor re-drai- } \\
\text { nage }\end{array}$ & $9(32,1 \%)$ & 0 \\
$\begin{array}{l}\text { antibiotic } \\
\text { type antibiotic }\end{array}$ & $18(78,3 \%)$ & 5 \\
$\begin{array}{l}\text { Beta-lactam (peni-, amoxi-, } \\
\text { flucloxacilline, augmentin) }\end{array}$ & $8(44,4 \%)$ & 0 \\
$\begin{array}{l}\text { Cefalosporine (cefuroxim) } \\
\text { Fluoroquinolones (ciprofloxa- } \\
\text { cine) }\end{array}$ & $5(27,8 \%)$ & \\
$\begin{array}{l}\text { Lincomycine (clindamycine) } \\
\text { Cefuroxim }+ \text { aminoglycoside }\end{array}$ & $1(5,6 \%)$ & \\
(gentamicine) & $2(11,1 \%)$ & \\
Cefuroxim + amoxicilline & $1(5,6 \%)$ & \\
\hline
\end{tabular}

n.b. niet beschikbaar

percutane drain in situ had en een derde van patiënten meerdere drainages nodig had. Uit een recent reviewartikel van Lee et al. worden overeenkomstige resultaten gepresenteerd met een mediane drainageduur van 10-20 dagen en een re-drainage in $20-25 \%$ van de gevallen [11]. Bij relatief kleine lymfoceles is behandeling met alleen antibiotica ook een mogelijkheid. Omdat in ons cohort vaak lymfoceles optraden met een doorsnee $>5 \mathrm{~cm}$, waarmee een risico bestaat op verminderde penetratie, werd niet alleen behandeld met antibiotica, maar werd er de voorkeur aan gegeven ook drainage te verrichten.

Een van de vragen die deze studie oproept, is hoe de lymfoceles geïnfecteerd raken. Omdat er soms veel tijd verstreek tussen de ingreep en de presentatie lijkt het minder waarschijnlijk dat de infectie optreedt door bacteriën die zijn ingebracht tijdens de ingreep zelf. Voor lymfoceles op korte tot middellange termijn zou er sprake kunnen zijn een laaggradige infectie van de lymfocele, die opspeelt bij verminderde weerstand. Waarschijnlijker is echter dat een persisterende lymfocele via hematogene route secundair wordt geïnfecteerd. Dit komt ook overeen met de bevinding dat de meeste bacteriën uit de kweken Gram-positieve bacteriën waren met huid als normale habitat. Profylactische preoperatieve antibiotica gebaseerd op urinetesten zijn dan waarschijnlijk slechts beperkt effectief. Gezien het lange interval tussen de operatie en de klachten is het echter de vraag of geïnfecteerde lymfoceles voorkomen kunnen worden door preoperatieve antibiotische profylaxe. Grotere winst kan behaald worden met het verminderen van het totaal aantal persisterende lymfoceles.

Er is veel onderzoek gedaan naar risicofactoren voor persisterende lymfoceles. Het peritoneum wordt beschouwd als een natuurlijk absorberend oppervlak voor lymfevocht. Om die reden veronderstellen veel chirurgen dat een trans- 
peritoneale benadering geassocieerd is met een lagere incidentie van lymfoceles. Daarentegen toonde een retrospectieve cohortstudie met 3.138 patiënten geen significant verschil in incidentie tussen een extraperitoneale en transperitoneale robotgeassisteerde radicale prostatectomie [10]. Een recent reviewartikel van Lee et al. concludeert eveneens dat de rol van extra- of transperitoneale benadering bij het vormen van lymfoceles niet eenduidig is [11]. Een risicofactor waar de literatuur het eens over lijkt te zijn, is het aantal gereseceerde lymfeklieren. Hoe meer lymfeklieren er worden verwijderd, hoe groter het risico op het ontstaan van een lymfocele $[4,9,11]$. Het is opmerkelijk dat in ons cohort een relatief hoge incidentie is gevonden, ondanks het feit dat er een standaard lymfeklierdissectie is verricht in plaats van de tegenwoordig gangbaarder extended PLKD (waarbij het percentage infecties dus mogelijk nog hoger zou kunnen zijn). Waarschijnlijk is de hoge incidentie grotendeels te verklaren door de langdurige followup.

Een ander punt van discussie is het gebruik van profylactische antistolling, omdat lymfevocht dezelfde stollingsfactoren bevat als plasma. Gotto et al. vonden een 6,7 keer hoger risico op het optreden van een lymfocele bij profylactisch gebruik van laagmoleculairgewichtheparine (LMWH). Andere studies vonden echter geen correlatie, waardoor ook dit onderwerp vooralsnog controversieel blijft [9, 11]. Eerdere studies hebben aangetoond dat het peroperatief plaatsen van drains hematomen in het bekken kan voorkomen, maar dat deze drains het risico op lymfoceles niet verminderen. Er is wel enig bewijs dat peritoneale fenestratie leidt tot minder lymfoceles. Stolzenburg et al. beschrijven een significante vermindering van lymfoceles na het verrichten van bilaterale fenestratie bij extraperitoneale laparoscopische lymfeklierdissectie [12]. Op basis van de beschikbare literatuur verdient fenestratie naar onze mening de voorkeur boven drainplaatsing.

De invloed van externe radiotherapie op de vorming van lymfoceles wordt in de huidige literatuur van de urologie niet beschreven, omdat het in de meeste cohorten lymfeklierdissecties ten tijde van een prostatectomie betreft. In de gynaecologische chirurgie zijn echter enkele artikelen verschenen waarin radiotherapie als risicofactor wordt aangehaald [13].

Aangezien tot op heden nog geen betrouwbare niet-invasieve diagnostische beeldvormingsmodaliteit beschikbaar is voor het opsporen van kleine lymfekliermetastasen wordt lymfadenectomie vooralsnog beschouwd als gouden standaard voor regionale lymfeklierstadiëring. Nieuwe diagnostische mogelijkheden, zoals de PSMA-PET, zullen in de toekomst het gebruik van invasieve stadiëringsmethoden zoals PLKD mogelijk reduceren en daarmee ook het risico op lymfoceles [14-16].
Onze studie is gelimiteerd door de retrospectieve aard ervan. Een prospectieve studie over lymfoceles met een follow-up van ten minste 18 maanden is echter uitdagend. Maar indien wij, vanwege het retrospectieve karakter van deze studie, gedraineerde lymfoceles hebben gemist, dan verstérkt dat juist onze conclusies.

\section{Conclusie}

Onze data tonen een incidentie van $10 \%$ symptomatische lymfoceles na PLKD waarvoor drainage noodzakelijk was. De opvallendste bevinding is dat de helft van de patiënten zich pas na meer dan een maand na de lymfeklierdissectie presenteert, waarbij het interval tussen operatie en klachten zelfs oploopt tot 17 maanden. Geïnfecteerde lymfoceles zijn, gezien langdurige en multipele drainages, geassocieerd met hoge ziektelast voor de patiënten.

Open Access This article is distributed under the terms of the Creative Commons Attribution 4.0 International License (http:// creativecommons.org/licenses/by/4.0/), which permits unrestricted use, distribution, and reproduction in any medium, provided you give appropriate credit to the original author(s) and the source, provide a link to the Creative Commons license, and indicate if changes were made.

\section{Literatuur}

1. Williams SK, Rabbani F. Complications of lymphadenectomy in urologic surgery. Urol Clin North Am. 2011;38(4):507-18.

2. Ploussard G, Briganti A, Taille A de la, Haese A, Heidenreich A, Menon M, et al. Pelvic lymph node dissection during robot-assisted radical prostatectomy: efficacy, limitations, and complications-a systematic review of the literature. Eur Urol. 2014;65(1):7-16.

3. Hamada A, Hwang C, Fleisher J, Tuerk I. Microbiological evaluation of infected pelvic lymphocele after robotic prostatectomy: potential predictors for culture positivity and selection of the best empirical antimicrobial therapy. Int Urol Nephrol. 2017;49(7):1183-91.

4. Capitanio U, Pellucchi F, Gallina A, Briganti A, Suardi N, Salonia A, et al. How can we predict lymphorrhoea and clinically significant lymphocoeles after radical prostatectomy and pelvic lymphadenectomy? Clinical implications. BJU Int. 2011;107(7):1095-101.

5. Freid RM, Siegel D, Smith AD, Weiss GH. Lymphoceles after laparoscopic pelvic node dissection. Urology. 1998;51(5A Suppl):131-4.

6. Solberg A, Angelsen A, Bergan U, Haugen OA, Viset T, Klepp O. Frequency of lymphoceles after open and laparoscopic pelvic lymph node dissection in patients with prostate cancer. Scand J Urol Nephrol. 2003;37(3):218-21.

7. Tremp M, Sulser T, Seifert HH. Delayed infection of a pelvic lymphocele following robotic radical prostatectomy and pelvic lymphadenectomy: two cases. Urol Int. 2009;83(4):479-81.

8. Orvieto MA, Coelho RF, Chauhan S, Palmer KJ, Rocco B, Patel VR. Incidence of lymphoceles after robot-assisted pelvic lymph node dissection. BJU Int. 2011;108(7):1185-90.

9. Gotto GT, Yunis LH, Guillonneau B, Touijer K, Eastham JA, Scardino PT, et al. Predictors of symptomatic lymphocele after radi- 
cal prostatectomy and bilateral pelvic lymph node dissection. Int J Urol. 2011;18(4):291-6.

10. Horovitz D, Lu X, Feng C, Messing EM, Joseph JV. Rate of symptomatic lymphocele formation after extraperitoneal vs transperitoneal robot-assisted radical prostatectomy and bilateral pelvic lymphadenectomy. J Endourol. 2017;31(10):1037-43.

11. Lee HJ, Kane CJ. How to minimize lymphoceles and treat clinically symptomatic lymphoceles after radical prostatectomy. Curr Urol Rep. 2014;15(10):445.

12. Stolzenburg JU, Wasserscheid J, Rabenalt R, Do M, Schwalenberg $\mathrm{T}$, McNeill A, et al. Reduction in incidence of lymphocele following extraperitoneal radical prostatectomy and pelvic lymph node dissection by bilateral peritoneal fenestration. World $\mathrm{J}$ Urol. 2008;26(6):581-6.

13. Weinberger V, Cibula D, Zikan M. Lymphocele: prevalence and management in gynecological malignancies. Expert Rev Anticancer Ther. 2014;14(3):307-17.

14. Maurer T, Gschwend JE, Rauscher I, Souvatzoglou M, Haller B, Weirich G, et al. Diagnostic efficacy of (68)gallium-PSMA positron emission tomography compared to conventional imaging for lymph node staging of 130 consecutive patients with intermediate to high risk prostate cancer. J Urol. 2016;195(5):1436-43.

15. Budaus L, Leyh-Bannurah SR, Salomon G, Michl U, Heinzer H, Huland $\mathrm{H}$, et al. Initial experience of (68)ga-PSMA PET/CT imaging in high-risk prostate cancer patients prior to radical prostatectomy. Eur Urol. 2016;69(3):393-6.

16. Herlemann A, Wenter V, Kretschmer A, Thierfelder KM, Bartenstein P, Faber C, et al. (68)Ga-PSMA Positron Emission Tomography/Computed Tomography Provides Accurate Staging of Lymph Node Regions Prior to Lymph Node Dissection in Patients with Prostate Cancer. Eur Urol. 2016;70(4):553-7.

drs. E. Bovelander anios urologie

dr. O.R. Brouwer aios urologie

drs. E.J. van Gennep uroloog

dr. R.F.M. Bevers uroloog

dr. K.T. Buddingh aios urologie 